\title{
Experiences and reflections on three years of CPS Summer schools within EIT Digital
}

\author{
Daniela Cancila \\ CEA, LIST \\ CEA Saclay - F91191 \\ Gif-sur-Yvette Cedex \\ daniela.cancila@cea.fr \\ Wolfgang Birk \\ Control Engineering Group \\ Lulea University of technology \\ - 97187 Lulea, Sweden \\ Wolfgang.Birk@ltu.se
}

\author{
Valeria Nuzzo \\ ECE \\ 75007 Paris - France \\ valeria.nuzzo@ece.fr \\ Fredrik Asplund \\ KTH Royal Institute of \\ Technology \\ Stockholm - Sweden \\ fasplund@kth.se
}

\author{
Milena Stoycheva \\ UniversitÃă di Trento \\ Via Sommarive 9, 38123 \\ Trento - Italy \\ milena.stoycheva@unitn.it \\ Martin Torngren \\ KTH Royal Institute of \\ Technology \\ Stockholm - Sweden \\ martint@kth.se
}

\begin{abstract}
This article provides an overview of current European Commission effort in term of educational innovation to reduce the gap between research and industry which still is a barrier to the economic development. Entrepreneurial innovation \& education driving Europe's digital transformation (EIT Digital for short) is an European-based initiative fostering I\&E (innovation and entrepreneurship) by integrating education, research and business at different educational levels. For instance in EIT master programmes, students work together with industries and academics to have a faster go-to-market of research results. Summer schools are part of the master programs; three of them have been organised related to CPS (cyber-physical systems), critical infrastructure and, more recently, Industry 4.0. Past and present events are discussed and the experience from these events is reported. It is further analysed how the general setup of the summer school program is affecting the educational aspects and achievement of the intended learning outcomes.
\end{abstract}

\section{Keywords}

Cyber-Physical System European summer school, Innovation and Entrepreneurship and CPS interrelationship

\section{INTRODUCTION}

In the last decades, we have witnessed an increase of numerous funding efforts across Europe devoted to reinforce the collaboration between research institutes and industries to boost innovation (e.g. H2020 calls). At this regard, most the economist are considering innovation as a major force in economic growth [14]. However, economical studies confirm that technological innovation could be unprofitable, if eco-

Permission to make digital or hard copies of all or part of this work for personal or classroom use is granted without fee provided that copies are not made or distributed for profit or commercial advantage and that copies bear this notice and the full citation on the first page. Copyrights for components of this work owned by others than the author(s) must be honored. Abstracting with credit is permitted. To copy otherwise, or republish, to post on servers or to redistribute to lists, requires prior specific permission and/or a fee. Request permissions from Permissions@ acm.org.

WESE'16 October 02-07 2016, Pittsburgh, PA, USA

Copyright is held by the owner/author(s). Publication rights licensed to ACM.

ACM 978-1-4503-3897-4/15/10 . .\$15.00

http://dx.doi.org/10.1145/2832920.2832924 nomic performance trough time is not taken in the right consideration $[14,12]$. This last concept is also highlighted by the European Artemis (Advanced Research \& technology for Embedded Intelligence and Systems) initiative which points out the greater impact and quick-to-markets results as the target priorities for the next coming period (2017-2025) [2].

In this respect, the recent European funding initiatives to directly address the gap between research results and industrial products are based on some challenges, among them: The use and the development of mature tools, which aim to accelerate innovation [7]; A focus on social and economic impact of research and industrial results [10]; The development of an ecosystem based on three pillars, education, science and industry [3].

To address this last challenge, educational activities and pedagogical teachings need to change, promoting entrepreneurship - inspired education of the future innovators starting from their graduate studies. Today, European universities strongly encourage students to include an industrial stage in their curricula, promoting a collaborative and interdisciplinary work among students, and addressing scientific aspects by starting from and return to real applications under a social and environment analysis. These initiatives as well as the increase of further implication of companies to the university programs are positively valuated at European level. For example, Artemis clearly states that the change in the education proves the need to form the new generation of engineers to better serve industry innovation [1].

In this vein, EIT Digital acts to support go-to-market projects, and innovation based education programs that are compliting the existing technical programs (doctoral, master and summer school) with the aim to boost technology based creativity and innovation in line with the European commission expectations. EIT Digital is an ambitious European initiative, which has been promoted about ten years ago under J.M. Barroso European presidency: "The mission of EIT Digital is to foster digital technology innovation and entrepreneurial talent for economic growth and quality of life in Europe. EIT Digital brings together entrepreneurs, (...) 
SMEs, start-up, universities and research institutes" [8]. The education program in EIT Digital aims to accelerate innovation to the market.

The authors of this work have been involved for a number of years in the organisation of Cyber Physical Systems (CPS) summer schools on behalf of EIT Digital. The experience and reflections from these can be used to tailor future summer school events on similar topics and, more in general, to suggest coupling two different topics: CPS and Innovation and Entrepreneurship (I\&E).

CPS combine a cyber side (computing and networking) with a physical side (mechanical, electrical, and chemical processes) $[15,5]$. In many cases, CPS are autonomous systems, which are able to dynamically change their behavior. I\&E adresses innovation as "the combination of an inventive process and an entrepreneurial process to create new economic value for defined stakeholders" [11]. This combination is considered the key to address global challenges of the 21st century" [13].

\section{CYBER-PHYSICAL SUMMER SCHOOL}

Cyber-Physical System (CPS) Summer School extends over two weeks. It concerns cutting-edge advances in embedded systems, networks, internet-of-things, model-based systems engineering, mechatronics and robotics. Moreover, lectures also focus on drafting a business plan, performing market studies, exploring social impact. An interactive teaching approach is adopted, based on case studies and team work. A team project is developed during the two weeks. Students are motivated to have a critical thinking (including social aspects), thanks to debate, exercises, discussions, firstly evaluation of their idea by experts' commission. Moreover, students are guided to prepare a pitch to present their work for the final projects competition. The winner could access to an EIT Digital financial support to realize their work. The underlying idea is to motivate the students' team and support the realization of a brilliant idea (if any).

The success of a CPS Summer School is mainly evaluated by the students' feedback. The general document template is shared by all EIT Digital Summer School and customised to the CPS Summer School. In this way, EIT Digital strengthens the comparison among their schools. The summer school is evaluated through a questionnaire regarding its organization (hotel, lunch, social event ... ); innovation and entrepreneurship aspects; and technical program. Both open and closed questions allowed for ranking the summer school and providing detailed feedback on valuable changes, for example what can be better and what could be removed and/or introduced for the next edition. Another important evaluation is the feedback of the organisers, which is directly provided to EIT Digital staff. The EU commission, which supports the schools, should be convinced each year to the add value of the school by the EIT Digital staff.

\section{LOCAL ORGANIZATION}

The first CPS Summer School was organized in Trento during the summer of 2014 and the second event was organized in Stockholm at KTH in the summer of 2015. In all events lecturers participated from partnering academic institutions and industry in order to contrast the different aspects of technological development and the transformation of the results into products and even businesses surrounding the newly developed technology.

\subsection{CPS Summer School at KTH in Stockholm}

Generally, the second year of the summer school had a similar setup as the first year, but was collocated with other summer school events within EIT Digital, which also took place in Stockholm. The division of Mechatronics at KTH Royal Institute of Technology hosted the 2015 CPS Summer School in collaboration with LTU Lulea University of Technology. The program was spread over eleven days (including Saturday) for a total of 77 hours [4]. It consisted of: technical lectures (25 hours); prototyping laboratory exercises (13 hours); I\&E courses (34 hours); administration part (3 hours) The technical lectures addressed:

- Challenges, trends and prototyping on CPS ;

- Critical infrastructures with respect to risk and safety in integrated systems, machine learning, and mobile network perspective.

The pitch event was set in the evening of the tenth day.

\subsubsection{Student feedback and reflections}

Students evaluated the school as strong in regard to administration, syllabus, information, activities, lectures, project work and industrial connection, even if the demanding schedule was at times seen as too exhausting. Many of the student's specific comments on the summer school related to the limited perspective that one acquires as a participant, since all organization requires trade-offs between what is ideal, practical and possible, respectively. However, the following was highlighted as relevant for the future organization of the CPS Summer Schools:

1) The prototyping lab exercises were too challenging for some students, but also trivial to complete for others. This is related to the diversity in background of different students, and that physical equipment is usually required for more advanced CPS lab exercises. Essentially the problem was the large effort required to set up each exercise involving physical equipment and the difficulty in aiming such exercises towards students with different skill sets. The suggestion for future summer schools were that EIT Digital would create a pool of moveable or remotely usable equipment for CPS lab exercises. The EIT network as a whole could thereby support different student specializations and levels of experience by distributing the effort of creating and maintaining advanced CPS lab exercises.

2) Different lecture topics were interesting to different students, also depending on their diversity in background. Due to the many CPS specializations featured throughout the syllabus, some students felt fragmented after losing focus during some lectures. It was therefore suggested that lecturers would instead be given the opportunity to plan for longer sessions that would run in parallel. Common sessions would then allow for tying the program together, while specialized sessions could be chosen based on interest. 


\subsection{CPS Summer School at ECE in Paris}

ECE Paris School of engineering in Paris [6] hosts the EIT Digital summer school on Cyber Physical Systems, organized in collaboration with the French Alternative Energies and Atomic Energy Commission (CEA) [16], from June 27th to July 8th, 2016.

Most of the participants are students involved in the EIT Digital Master. The reaming came from master, $\mathrm{PhD}$ and research centers. The participants have a background in science and engineering and coming from high-ranking universities in Europe such as KTH-Sweden, University of TwenteNetherlands, and University of Trento-Italy.

The organization of 2016 School intentionally capitalizes on the past edition at KTH in Stockholm. Then the keypersons, which has been involved in the CPS Summer School 2015, was invited to join the 2016 edition. They provide: two main technical talks, on "challenges and trend on CPS" and "Critical Infrastructure", laboratory exercises and an involvement with team students (over 6 full days) to enhance the overall quality of their work.

Unlike the previous edition, the Paris edition devotes about $80 \%$ of the time to Innovation and Entrepreneurship (I\&E) courses, provided by Matteo Bonifacio and Milena Stoycheva. One of the major reasons for that is the fact that this is a course that gives credits to students within the EIT Digital Master School Program. I\&E highlights the importance of a social and economic impact as an essential background to look forward for a technical solution, which is elaborated during the CPS Summer School by the students with the support of the I\&E professors.

\subsubsection{Program and organization}

Students work in team of 5 participants along two weeks. Each team introduces an idea of a project and develops it via a support of business cases. Effective team work is particularly appreciated by the I\&E professors. Students are also prepared to pitch their idea and project.

Evaluations of the projects are carried out during and after the end of the school. During the two weeks, two main evaluations are established by a given commission of experts and teaching: at the end of the first week, the evaluation aims to provide an early feedback of the idea and the associated business plan; at the end of the second week, the evaluation decides the winning project. During the two weeks, speakers give feedback to all students team to improve their project with their expertise.

Finally, at the end of July, after three weeks from the end of the CPS Summer School, students must submit a written report of their project to the I\&E professors to the final evaluation. As we introduced in Section 2, credits, taken by the students from the EIT Digital CPS Summer School, integrates the credits coming from the EIT Digital master.

The CPS Summer School provides a multimedia section. Photos are taken during the day and published in the facebook page and in the class the day after. The main advantage of this work has been the creation of an environment of aggregation among the students. Consequently, the teach- ing courses, which strongly promotes the work-team, have been easily accepted by the students.

\subsubsection{Student feedback}

The students appreciated the I\&E coaching and technical lectures. They suggest introducing company visits and more technical topics concerning CPS.

\subsubsection{Reflections}

The approach socially-driven was very well accepted and integrated by the students. In two weeks they were able to understand the key for success in entrepreneurial initiatives and perform a deep analysis of social impact, markets, competitors, potential investors, therefore defocusing from the technological solution.

The 2016 Edition winner project was to develop a platform for connecting refugees to locals leading to the creation of new businesses (ex: phone forfeits for keeping in touch, ..).

Finally, a greater industrial involvement and, if it is possible, manufacturing visits could be considered for the next edition to strengthen the European target priorities further (See Section 1).

\section{DISCUSSION AND RECOMMENDATION}

CPS is a large topic covering Industry 4.0 and CPS-IoT systems, to quote some among the most illustrate examples. Design, development and analyses of CPS encompass heterogeneous systems and demand a working teams with different background and how-know. As showed in the 2015 edition, the risk and safety analyses of integrated systems is a sensible industrial topic which is not yet fixed. The existing industrial technical solutions are still not adequate to properly deal with dependability in CPS. Then, the teaching of CPS could turn into a thorny challenge because this topic inherently overcomes several technical and scientific issues. A clear selection of the scope and the considered viewpoint is then necessary to go in depth - thus limiting the risk to achieve a broad and superficial course.

The approach taken in the CPS Summer Schools guides a student from an abstract notion to the related concrete one, thanks to iterative lessons and team work (during the course). For example, in the 2015 and 2016 editions, the talk on "challenge and trend on CPS" interleaves definitions and real examples of CPS with questions and live discussions with the students on the notions just introduced. Hence, theory and practice are not still opposite anymore: both are needed to form the innovators of tomorrow in line with the European directives.

At educational level, an additional effort could be considered to directly connect I\&E and CPS. The underlying idea is to inverse the old European trend: from the existing technology to look forward for social and economic impacts. A structural link between I\&E and CPS means to consider time performance, the social context and the best technology that fix it. This increasing European trend provides the core of the "CPS disruptive technologies". Therefore, we strongly suggest introducing I\&E into CPS courses. The main difficulty, however, is to "correctly" set-up the proportion between the 
two topics. Both of them need time to expect good results as well as a deep introduction and analysis. Nevertheless, if a program includes a majority of I\&E topics, the risk could occur in the delocalization of the technical how-know, with a consequent loss of economical competiveness; if a program includes a majority of CPS topics, the risk is to fall into the old trend where a technology not necessarily corresponding to a real innovation and impact on our society. In our experience, the balance between I\&E and CPS is not fixed yet and should be depending on the profile of the students.

Based on three years of expertise in the organization of CPS Summer Schools, we point out the importance in the involvement and the physical presence of industry in the courses. It could improve the technology, entrepreneurship and social impact in the summer schools and, or in general, of a CPS university course. We end this section by highlighting the connection between the CPS Summer School and the related Doctoral program [9]. As we briefly show, the way forward of the CPS Summer School is in line with the Doctoral Program. Here, doctoral students are hosted at the Doctoral Training Centres which provide a multi-disciplinary environment. The $\mathrm{PhD}$ experience is an intensive research experience where the $\mathrm{PhD}$ try to understand the research problem they have to solve, formulate it well and propose new solutions that they have to validate with different proof of concepts. Here comes a new and challenging experience brought up by the Doctoral Training Centre under the EIT Digital flag where the $\mathrm{PhD}$ students will have a unique opportunity to deal with innovation and entrepreneurship in new technologies. The PhD students will learn to give another flavour to their research work through the build-up of a realistic business assessment of their research work which can lead to a start-up or entrepreneurship in innovation. We think that both initiatives, CPS Summer School and Doctoral Program, represent a positive answer to the European target priorities on ICT.

\section{CONCLUSIONS}

The current European trend is to address innovation as a prominent role to the economical grown. A particular attention is then devoted to entrepreneurship graduate education of the future innovators. In this respect, CPS Summer Schools are a means to strengthen such a direction.

In this paper, we have introduced the organization of the CPS Summer Schools, the students' feedback and our reflection. In order to assess the novelty in the European scenario, CPS Summer Schools integrate I\&E topics into CPS courses. The ides is firstly to look at the social and impact aspects and secondly to look forward to technologies that fix it. This combination could be adopt into university CPS courses. However, one of our next major challenges in teachings CPS is to find the correct balance between these topics.

\section{ACKNOWLEDGMENTS}

Special thanks go to Giulia Corsi for the overall organization and to Giulio Dallatorre for the multimedia part. We would also like to thank all persons involved in the organisation of the CPS summer schools. A special gratitude goes to EIT Digital for their funding support in setting up the CPS summer schools. Finally, we thank the WESE 2016 reviewers for their valuable suggestions and recommendations.

\section{ADDITIONAL AUTHORS}

Additional authors: Matteo Bonifacio (Università di Trento, email: matteo.bonifacio@unitn.it) and and Belgacem Ben Hedia (CEA List, email: belgacem.benhedia@cea.fr) and Hakima Chaouchi (Telecom, Sud Paris, Institut Mines Telecom, email: jchauchi@telecom-sudparis.eu) .

\section{REFERENCES}

[1] Artemis. Business Impact \& Metrics proof of the success in the Artemis Programme, 2016. http://www . artemis-ju.eu/publications.

[2] ARTEMIS. Research Agenda 2016. http://www.ecsel-austria.net/newsfull/items/artemisstrategic-research-agenda-2016-sra-31.html.

[3] J. M. Barroso. Science and innovation, an essential factor for competitiveness and growth in europe. In Science and Innovation in Europe: the keys to tomorrow's growth. 2012.

[4] CPS Summer School Program 2015. https://www.kth.se/polopoly\_fs/1.564466!/CPS \ $\% 20$ Summer $\backslash \% 20$ School, $\backslash \% 20$ Stockholm $\backslash \% 20-\backslash$ $\% 20 \mathrm{Final} \backslash \% 20$ Programme.pdf.

[5] CyPhERS FP7 Project. CPS: State of the Art. http: //www.cyphers.eu/sites/default/files/D5.1.pdf.

[6] ECE Graduate School of Engineering. Paris. . http://www.ece.fr/school-of-engineering.

[7] ECSEL JU. Decision of the governing board of the ECSL joint undertaking: Adopting the ECSEL Multi-annual Strategic Plan 2016. http://ecsel.eu/web/downloads/Calls/ecsel_gb_ 2015_46_-_masp_2016_v3.pdf.

[8] EIT Digital. http://www.eitdigital.eu.

[9] EIT Digital Doctoral School. http://www . doctoralschool.eitdigital.eu.

[10] European Commission. Horizon 2020 indicators. https://ec.europa.eu/programmes/horizon2020/en/news/horizon-2020-indicators-assessing-results-andimpacthorizon.

[11] K. Hindle. The relationship between innovation and entrepreneurship:easy definition, hard policy. In $A G S E$ International Entrepreneurship Research Exchange, 2009.

[12] D. C. North. Economic Performance Through Time: The Limits to Knowledge. Economic History, 1996.

[13] OECD. Smes, entrepreneurship and innovation, 2010.

[14] N. Rosemberg. Innovation and economic growth. OECD, December 2004.

[15] A. Sangiovanni-Vincentelli, W. Damm, and R. Passerone. Taming Dr. Frankenstein: Contract-based design for cyber-physical systems. European Journal of Control, 18(3):217-238, 2012.

[16] The French Alternative Energies and Atomic Energy Commission (CEA) From research to Industry . http://www.cea.fr/english. 